Araştırma Makalesi-Research Article

\title{
Temper Haddelemede Merdane Parametrelerinin ERD6112 Kalite Sac Malzemelerin Pürüzlülük Transferine Etkisinin Deneysel İncelenmesi ${ }^{1}$
}

\begin{abstract}
Fatih BAŞOĞLU ${ }^{1 *}$, Naci KURGAN ${ }^{2}$
Geliș / Received: 31/07/2019

Revize / Revised: 21/11/2019

Kabul / Accepted: 28/11/2019

ÖZ

Sac malzemelerde yüzey kalitesinin, düzlemselliğin ve yüzey pürüzlülüğünün önemli olduğu yerlerde malzemenin temper haddeden geçirilmesi gerekmektedir. Malzemelerin mekanik özelliklerinin homojenleştirildiği ve istenilen pürüzlülükte üretildiği işlem olan temper haddeleme, yaklaşık \%1 uzamanın verildiği bir ütüleme haddesidir. Bu çalışmada, homojen bir pürüzlülük transferi için hangi şartlarda temper haddeleme yapılması gerektiği ve malzeme özelliklerinin bu pürüzlülük transferini ne ölçüde etkileyeceği araştırılmıştır. Bu kapsamda, ERD6112 kalite sac malzemeler laboratuar şartlarında farklı devir ve farklı ezme miktarlarında temper haddeleme ile pürüzlendirilmiş ve pürüzlülük transferini etkileyen ezme miktarı, merdane pürüzlülük değeri, haddeleme hızı ve haddeleme kuvveti gibi parametreler deneysel olarak incelenerek sonuçlar değerlendirilmiştir. Bu çalışmada haddeleme kuvvetinin artmasıyla pürüzlülük transfer oranının arttığı sonucuna ulaşılmıştır. ERD6112 kalite malzeme için yüksek ezme oranlarında ve pürüzlülük değeri yüksek merdane kullanılması durumunda pürüzlülük transferinin arttığı gözlenmiştir. Pürüzlülük transferini etkileyen bir diğer parametrenin ise hız olduğu tespit edilmiştir. ERD6112 kalite malzeme için yüksek devirlerde pürüzlülük transferinin arttığı görülmüştür.
\end{abstract}

Anahtar Kelimeler- Haddeleme Hızı, Merdane Pürüzlüllüğ̈̈, Pürüzlüllük Transferi, Temper Haddeleme, Yüzey Pürüzlülüğ̈̈

\footnotetext{
1*Sorumlu yazar iletişim: fatih-basoglu@hotmail.com ( https://orcid.org/0000-0002-8216-1734)

Makine Mühendisliği Bölümü, Ondokuz Mayıs Üniversitesi, Mühendislik Fakültesi, Samsun, Türkiye

2İletişim: naci.kurgan@omu.edu.tr ( https://orcid.org/0000-0001-7297-7249)

Makine Mühendisliği Bölümü, Ondokuz Mayıs Üniversitesi, Mühendislik Fakültesi, Samsun, Türkiye
}

${ }^{1}$ Bu Makale Yüksek Lisans tezinden hazırlanmıștır. 


\title{
An Experimental Investigation of the Effects of the Roller Parameters in "Temper Rolling" on Roughness Transfer of ERD6112 Quality Sheet Materials
}

\begin{abstract}
The material should be tempered when surface quality, planarity and surface roughness are important in sheet materials. Skin pass mill which is the process in which the mechanical properties of the materials are homogenized and produced with the required roughness is a temper mill with about $\% 1$ elongation. In this study, it has been researched that in which conditions tempering should be performed for homogen roughness transfer and to what extent material properties have influence on this roughness transfer. In this context, ERD6112 quality sheet materials were roughened by tempering in various circulation and crushing quantity in laboratory conditions and the parameters such as crushing amount, roller roughness value, rolling speed and rolling force were experientially investigated and the results were evaluated. In this study, with the increase of the Rolling force, it was reached that rate of roughness transfer increased. It is observed that roughness transfer increased by using roller with high roughness value at the rate of high crushing for ERD6112 quality material. It was determined that speed was another parameter affecting roughness transfer. It was observed that roughness transfer increased at high revolutions for ERD6112 quality material.
\end{abstract}

Keywords- Rolling Speed, Roller Roughness, Roughness Transfer, Temper Rolling, Surface Roughness 


\section{GIRIŞ}

Makine imalat sektöründe malzemenin kullanılacağı şartlara bağlı olarak farklı özelliklerde malzemelerin kullanılmasına ihtiyaç vardır. Her malzeme farklı yüzey pürüzlülük, farklı sertlik ve farklı aşınma direnci değerlerine sahiptir. Sektördeki farklı ihtiyaçların karşılanması için birbirinden farklı imalat metotları kullanılmaktadır. İstenilen özeliklere ulaşmak için kullanılan imalat metotları bazen tek başına yetersiz kalmakta ve malzemelerin ikincil operasyonlara tabi tutulması gerekli hale gelmektedir. Bu ikincil operasyonlar ile parçalar istenilen yüzey sertliği, yüzey pürüzlülüğü, aşınma direnci vb. kriterlere ulaşmaktadır. Üretim için kullanılan talaşlı imalat yöntemleri (Tornalama, Frezeleme vb) ile parça yüzeylerinde belli bir yüzey kalitesine erişilebilmektedir. Haddeleme, işlevsel yüzeylerin talaş kaldırmadan ve ezerek, eksenleri etrafında dönen iki merdane arasından geçirilerek yapılan bir plastik şekil verme işlemidir. Kullanılan ezme sistemi ile haddeleme yapılacak parçaların yüzeyleri ezilerek yüzey karakteristiklerinde iyileşmeler gerçekleştirilir. Haddeleme makine imalat tekniği olarak öteden beri kullanılan bir son işlem operasyonudur [1]. Haddeleme, üretim hızı ve sürekliliği ile işlemin ve ürün kontrolünün kolay oluşu nedenleriyle en çok kullanılan plastik şekil verme yöntemidir. Plastik deformasyonun yapıldığı malzemelerin \%90 kadarı haddeleme ile şekillendirilir [2-3]. Soğuk haddeleme; malzemenin, yeniden kristalleşme sıcaklığının altındaki sıcaklıklarda yapılan haddeleme işlemidir. Sac, folyo, ince çubuk ve tel gibi küçük kesitli ürünlerin elde edilmesinde kullanılır [4]. Soğuk haddeleme, düzgün bir yüzey, hatasız boyutlar ve yüksek mukavemet özellikleri sağlamasına karşın, işlem için gerekli olan haddeleme kuvvetlerinin ve gücünün artmasına yol açar. Soğuk haddeleme, levhaların minimum boyutsal toleranslardaki kalınlıklarda, iyi yüzey, daha iyi mekanik özellikler ve aynı zamanda istenen fiziksel özelliklerde üretilmesini mümkün kılar [5]. Temper haddeleme ise soğuk haddelenmiş saca nihai özellikleri kazandırmak amacıyla uygulanan bitirme haddesidir. Malzemenin nihai şekillendirme öncesinde deformasyon yaşlanmasına uğramamas1, yüzey düzgünlüğü ve gerekiyorsa yüzey pürüzlülüğü bu özellikler arasındadır [6].

El-Axir, yaptığı çalışmalarda haddeleme için en uygun parametreleri belirleyebilmeyi amaçlamıştır. Bu çalışmalarda haddeleme operasyonlarında birçok etmenin önemli olduğunu gözlemiştir. Haddeleme operasyonunda haddeleme hızı, haddeleme kuvveti, haddeleme adımı ve paso sayısı gibi farklı haddeleme şartlarının yüzey mikro sertliği ve pürüzlülüğü üzerindeki etkilerini araştırmak üzere deneysel çalışmalar yapmıştır. Yaptığı deneysel çalışmalarda St-37 malzemeden iki farklı profil üzerinde araştırmalar yapmıştır. Yaptığı bu deneylerde numune parçalar üzerinde yağlama uygulamış ve kullanılan profilleri torna tezgahına bağlayarak haddeleme işlemi bu şekilde gerçekleştirilmiştir [7]. El-Axir yaptığ çalışmalarda deneysel sonuçlar ile matematiksel modelleme ile elde ettiği sonuçları karşılaştırmış ve aralarında iyi bir korelasyon olduğunu belirlemiştir. Hem yüzey mikro sertliği hem de yüzey pürüzlülüğü üzerinde mil hızı, haddeleme kuvveti, haddeleme adımı ve paso sayısının en önemli etkilere sahip parametreler olduğunu göstermiştir. Hassan ve arkadaşları, yaptıkları çalışmada yük, ilerleme, kullanılan takım sayısı gibi değişkenlerin haddeleme işlemi üzerindeki etkilerini incelemişlerdir. İş parçasının başlangıçtaki yüzey pürüzlülüğü ve sertliği parametrelerinin haddeleme aparatında kullanılan bilye çapının ve bu işlem içerisinde kullanılan yağlamanın haddelemeye etkileri araştırılmıştır. Deneyler sırasında yağlamanın yüzey daireselliği ve yüzey sertliğine olan etkilerini incelemişlerdir. Deney sonuçlarında başlangıçta belirlenen parametrelerin haddeleme prosesinde önemli etkilerinin olduğu belirtilmiştir [8]. Hassan, döküm alüminyum-bakır alaşım malzemeler üzerinde haddeleme ile ilgili araştırmalar yapmıştır. Alaşımlarda farklı haddeleme parametreleri (Haddeleme kuvveti, hızı ve adımı) kullanarak bu parametrelerin yüzey pürüzlülüğü ve yüzey sertliği üzerine etkilerini incelemiştir. Haddeleme deneylerinde haddeleme kuvvetinin hızının ve adımın artırılması ile yüzey pürüzlülügünün azaldığı tespit edilmiştir. Belirli bir limite kadar haddeleme kuvvetinin artması ile yüzey pürüzlülüğü azalmaktadır bu limit aşıldığında tekrar iş parçasının yüzey pürüzlülüğünde artma meydana gelmektedir. Haddeleme hızının artması da benzer bir etkiye neden olmaktadır sınır değer aşılınca iş parçasının yüzey pürüzlülüğünde artış meydana gelmektedir. Haddeleme adımının da test edilen diğer değişkenler gibi sınır aşıldığında yüzey pürüzlülüğünde bozulmalar meydana gelmektedir [9]. Hassan ve arkadaşları, soğuk şekillendirme çeşitlerinden kumlama (bilyeleme) ve haddeleme ile ilgili çalışmalar yapmıştır. Bu iki yöntemde plastik deformasyon ile metalik yüzey özelliklerinde geliştirme yapmaktadır. İlk yöntem yüzey pürüzlülüğünü artırırken ikinci yöntem ise birincinin aksine yüzey pürüzlülüğünü azaltmaktadır. Hassan ve Momami yaptıkları deneylerde kumlama işlemi uygulanmış parçaya haddeleme yaparak kumlama ile oluşan yüzey pürüzlülügünü azaltmak istemişlerdir. Alüminyum ve pirinç malzemeler üzerinde yapılan deneyler sonucunda metalik yüzey özellikleri kumlama ile iyileştirilmiş ve bu yüzeylerin kumlama işleminin ardından bilyeli haddeleme aparatı ile yapılan haddeleme 
işlemi ile daha da geliştirilebileceği deneysel olarak çıkarılmıştır. Yapılan deneylerde haddeleme adımı, hızı, bilye çapı ve paso sayısı gibi değişkenler sabit tutulup haddeleme kuvvetinin etkileri araştırılmıştır [10].

Sac malzemelerde yüzey görünümünün önemli olduğu, düzlemselliğin, yüzey pürüzlülüğü ve yüzey kalitesinin önemli olduğu yerlerde malzemenin temper haddeden geçirilmesi gerekmektedir. Temper haddeleme; yaklaşık \%1 uzamanın verildiği bir ütüleme haddesidir. Esasen incelmenin olmadığı bu haddede akma gerilmesinin üzerine çıkılarak ezilen malzeme, temper hadde sonrasında deformasyon yaşlanmasına uğraması beklenmeden nihai form verilirse belirgin akma görülmeyeceğinden dolayı daha iyi bir yüzey kalitesi elde edilmiş olur. Bobin kırıkları, malzeme yüzeyindeki dalgalı görünüm ve lüders bantlarının izleri bu hadde ile ortadan kaldırılır [11]. Çelik sacların, sıcak ve soğuk haddelemeye göre çok daha az ezmenin yapıldığı temper haddelemeye tabi tutulmasındaki amaçlardan biride malzeme yüzeyinde homojen yüzey pürüzlülüğü elde etmektir. Temper hadde, malzeme yüzeyinin pürüzlü olması istenen durumlarda pürüzlendirilmiş merdaneler ile yapilir.

Bu çalışmadaki amaç; sac yüzeyinde istenilen düzeyde ve homojen bir pürüzlülük transferi için hangi şartlarda haddeleme yapılması gerektiği ve malzeme özelliklerinin bu transferi ne ölçüde etkilediğidir. Yapılan deney sonuçlarına göre haddeleme parametreleri ile pürüzlülük değişimleri arasındaki ilişkiler incelenerek ERD6112 kalite derin çekme sacı malzemelerin haddeleme öncesi ve haddeleme sonrası malzeme yüzeyinde elde edilen pürüzlülük değerleri tespit edilmiştir. Ayrıca yapılan çalışmada malzeme pürüzlülük değerinin dar bir aralıkta olması gerektiğinden dolayı malzeme yüzeyinde yapılan çok sayıda pürüzlülük ölçümü sayesinde, pürüzlülük transfer oranına ilaveten, pürüzlülük dağılımındaki homojenliğin bir göstergesi olan standart sapma da hesaplanmıştır.

\section{MATERYAL VE METOD}

Bu çalışmada kullanılan malzeme ERD6112 kalite sac malzemedir. ERD6112 kalite sac malezemeler literatürde derin çekme sacı olarak geçmektedir. Şekil 1' de gösterildiği gibi Gersan firması tarafından temin edilen 1,8 mm kalınlığında ve $30 \mathrm{~mm}$ genişliğinde olan bu malzeme $300 \mathrm{~mm}$ uzunluğunda farklı hadde parametrelerinde 8 adet test yapılmak suretiyle eşit parçalar halinde kesilmiştir.

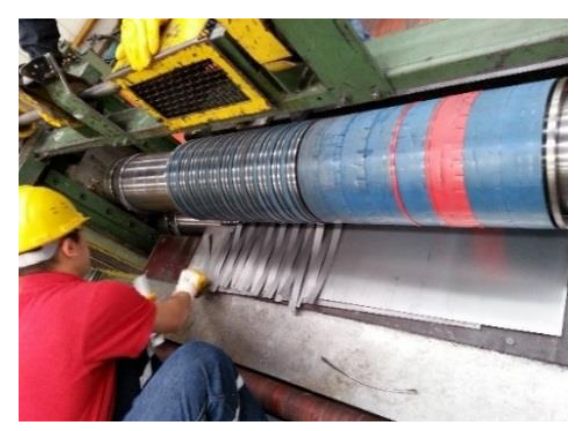

Şekil 1. Test numunelerinin hazırlanması

\section{A. ERD6112 Kalite Malzeme}

Erdemir 6112 kalite malzemeleri kullanım alanı olarak en çok endüstriyel uygulamalarda, beyaz eşya endüstrisinde ve çekme kalıpçılığında görmekteyiz. ERD6112 kalite malzemeye ait kimyasal özellik tablosu Tablo 1' de mekanik özellik tablosu ise Tablo 2' de verilmiştir [13]. 
Tablo 1. ERD6112 kalite malzemenin kimyasal özellikleri [12]

\begin{tabular}{ccccccc}
\hline Kalite & \%C & \%Mn & \%P & \%S & \%Si & \%Al \\
\hline ERD6112 & 0,036 & 0,204 & 0,010 & 0,006 & 0,007 & 0,070 \\
\hline
\end{tabular}

Tablo 2. Erdemir 6112 kalite malzemenin mekanik özellikleri [13]

\begin{tabular}{lll}
\hline Malzeme & \multicolumn{1}{c}{ Mekanik Özellikleri } \\
\hline & Çekme Dayanımı & $350 \mathrm{Mpa}$ \\
& Akma Dayanımı & $252,9 \mathrm{MPa}$ \\
\multirow{2}{*}{ ERD6112 } & Uzama & $\% 18,81$ \\
& Elastikiyet Modülü & $141,7 \mathrm{GPa}$ \\
& Poisson Oranı & 0,28 \\
& Özgül Ağırlığ & $7,83 \mathrm{~g} / \mathrm{cm}^{3}$ \\
\hline
\end{tabular}

\section{B. Haddeleme Düzenĕgi}

Şekil 2' de gösterilen haddeleme düzeneği 1,5 kw gücünde, 5-60 rpm devir sayılarında çalışmakta olup 100 ton kapasiteli bir loadcell (yük ölçer) ile teçhiz edilmiştir. Düzenekte kullanılan hadde merdaneleri 75 mm çapında olup birer çift 3,4 $\mu \mathrm{m}$ ve $8,5 \mu \mathrm{m}$ pürüzlüğe sahiptir. Farklı devir ve farklı ezme miktarlarında ERD6112 kalite sac malzeme üzerinde testler yapılmış ve bu testler sonucunda pürüzlülük transferine etki eden ezme miktarı, merdane pürüzlülük değeri, haddeleme hızı ve haddeleme kuvveti gibi parametreler kullanılan bu hadde düzeneğinde deneysel olarak incelenmiş ve sonuçlar yorumlanmıştır.

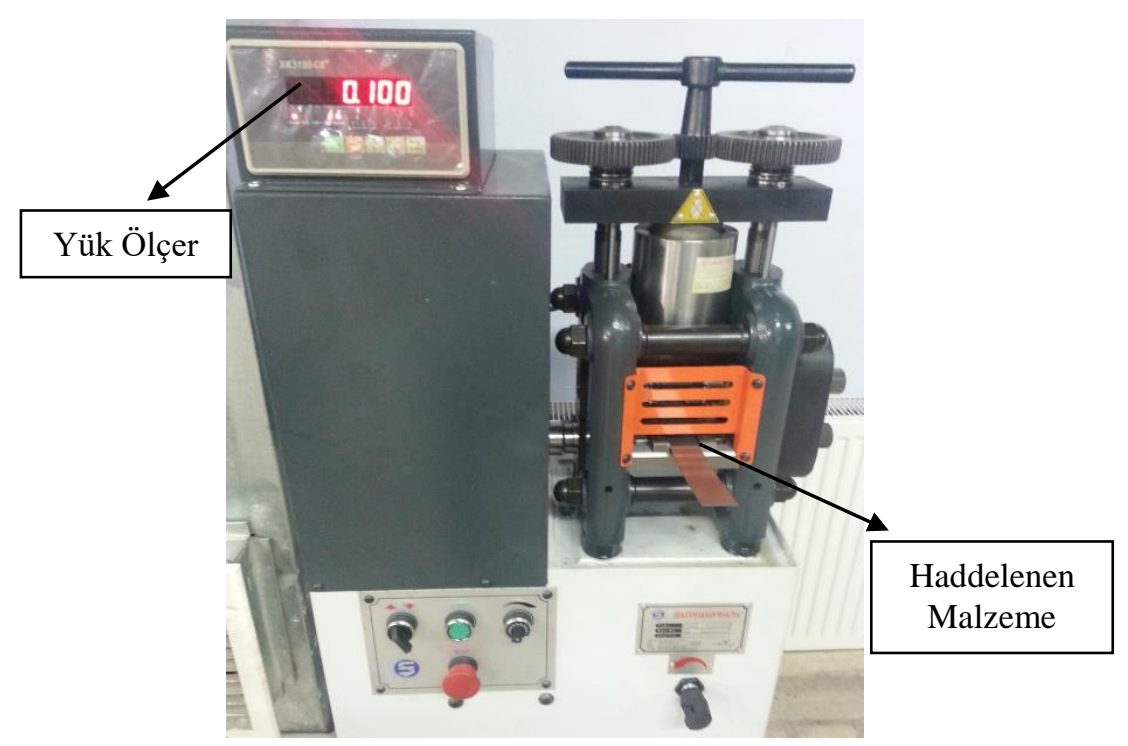

Şekil 2. Haddeleme düzeneği

Şekil 3' de haddeleme parametreleri ve hadde yükü üzerine yazılmış ERD6112 kalite sac malzeme test numunesi görülmektedir. Kullanılan notasyon ve haddeleme parametreleri Tablo 3' de gösterilmiştir. Bu notasyona göre E/1,8/8,5/10/30 ile gösterilen bir testin; 1,8 mm kalınlığında ERD6112 kalite sac malzemenin, $8,5 \mu \mathrm{m}$ pürüzlülüğünde merdane ile $10 \mathrm{~d} / \mathrm{dk}$ hızda, $30 \mu \mathrm{m}$ ezme miktarı verilerek haddeleme yapıldığı anlamına gelmektedir. Merdane pürüzlülüğünde alt limit olarak 3,4 $\mu \mathrm{m}$ pürüzlülük değerinde merdane seçilmesindeki amaç; Erdemir firmasında gerçekleştirilen haddeleme işlemlerinde çoğunlukla 3,5 $\mu \mathrm{m}$ pürüzlülük değerinde merdane kullanılıyor olmasıdır. Üst limit olarak ise çok pürüzlü merdane kullanarak iki merdane arasındaki pürüzlülük farklarını incelemektir. Devir sayısındaki limit ise haddeleme düzeneğinin 5-60 rpm devir sayılarında çalışmaktadır. Bu sebeple alt limit $10 \mathrm{~d} / \mathrm{dk}$ üst limit ise $50 \mathrm{~d} / \mathrm{dk}$ olarak seçilmiştir. Haddeleme düzeniği 100 ton 
BȘEÜ Fen Bilimleri Dergisi

6 (2), 344-356, 2019
BSEU Journal of Science DOI: 10.35193/bseufbd.599469

e-ISSN: 2458-7575 (http://dergipark.gov.tr/bseufbd)

yük kapasitesi altında çalı̧̧ı̆ğından dolayı ezme miktarı alt ve üst limitler bu kapasite dikkate alınarak verilmiştir. Fazla yük altında haddeleme işlemi gerçekleşirken malzemede kopma meydane gelmektedir.

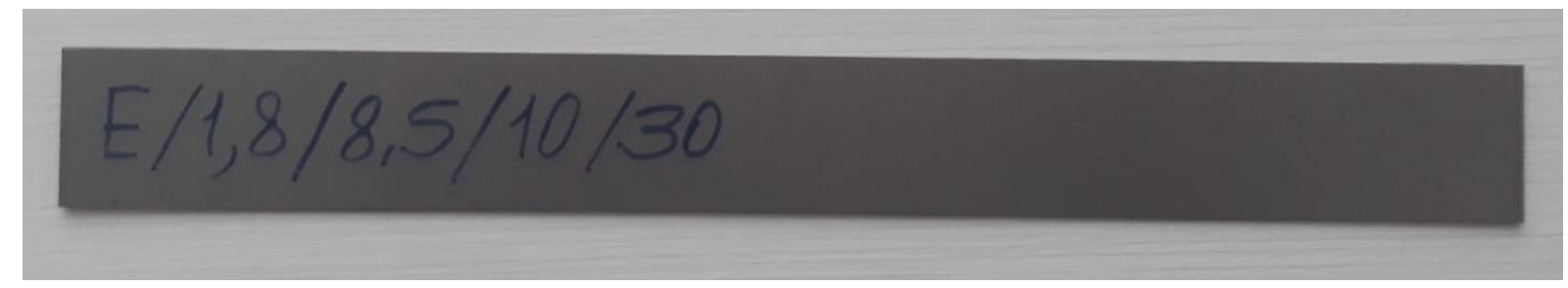

Şekil 3. Test numunesi

Tablo 3.Haddeleme parametreleri ve notasyon

\begin{tabular}{lccc}
\hline \multicolumn{3}{c}{ HADDELEME PARAMETRELERI } & A/B/C/D/E \\
\hline \multirow{2}{*}{ Malzeme Cinsi (A) } & İndikatör & \multicolumn{2}{c}{$\mathrm{E}$} \\
\cline { 2 - 4 } & Anlamı & \multicolumn{2}{c}{ ERD6112 } \\
\hline \multirow{2}{*}{ Malzeme Kalınlı̆̆ı (B) } & İndikatör & \multicolumn{2}{c}{1,84} \\
\cline { 2 - 4 } & Anlamı & \multicolumn{2}{c}{$1,8 \mathrm{~mm}$} \\
\hline \multirow{2}{*}{ Merdane Pürüzlüğ̈̈ (C) } & İndikatör & 3,4 & 8,5 \\
\cline { 2 - 4 } & Anlamı & $3,419 \mu \mathrm{m}$ & $8,476 \mu \mathrm{m}$ \\
\hline \multirow{2}{*}{ Devir Sayısı (D) } & İndikatör & 10 & 50 \\
\cline { 2 - 4 } & Anlamı & $10 \mathrm{~d} / \mathrm{dk}$ & $50 \mathrm{~d} / \mathrm{dk}$ \\
\hline \multirow{2}{*}{ Ezme Miktarı (E) } & İndikatör & 30 & 60 \\
\hline & Anlamı & $30 \mu \mathrm{m}$ & $60 \mu \mathrm{m}$ \\
\hline
\end{tabular}

\section{Kalınlı Ölçümü}

Türk Akreditasyon Kurumu (TÜRKAK) tarafindan uygunluğu görülen ve KBU Demir-Çelik Enstitüsü Metroloji Laboratuvarlarında bulunan Şekil 4' de görülmekte olan kalibreli Mitutoyo marka mikrometrelerle yapılan ölçümler neticesinde malzemenin incelme miktarı hesaplanmıştır. Bu testler neticesinde ezme miktarı ve haddeleme kuvveti sayısal verileri Tablo 4' de gösterilmiştir.

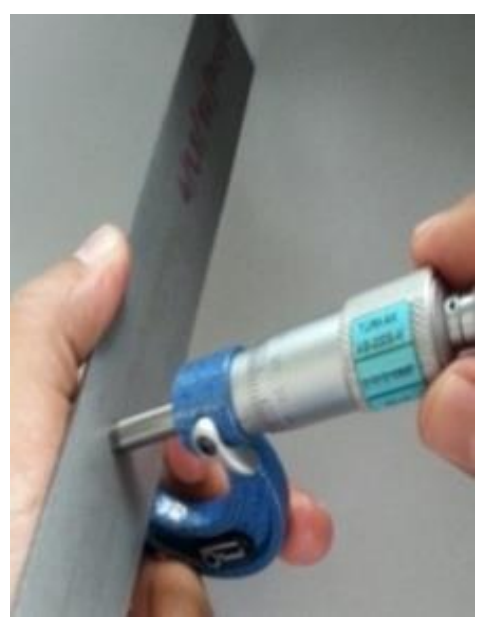

Şekil 4. Kalınlık ölçümü 
Tablo 4. ERD6112 kalite malzemeye ait ezme miktarı ve hadde kuvveti değerleri

\begin{tabular}{|c|c|c|c|c|c|c|}
\hline \multicolumn{7}{|c|}{ ERD6112 Kalite Malzeme } \\
\hline \multirow[b]{2}{*}{$\begin{array}{c}\text { Haddeleme } \\
\text { Parametreleri }\end{array}$} & \multicolumn{2}{|c|}{ Kalınlık $(\mu \mathrm{m})$} & \multirow{2}{*}{$\begin{array}{l}\text { İncelme } \\
\text { Miktarı } \\
(\mu \mathrm{m})\end{array}$} & \multirow{2}{*}{$\begin{array}{c}\text { Ezme } \\
\text { Miktarı } \\
(\mu \mathrm{m}) \text { Paso }\end{array}$} & \multirow{2}{*}{$\begin{array}{c}\text { İncelme/Ezme } \\
\text { Oranı }\end{array}$} & \multirow{2}{*}{$\begin{array}{c}\text { Hadde } \\
\text { Kuvveti } \\
(\mathrm{kN})\end{array}$} \\
\hline & $\begin{array}{l}\text { Haddeleme } \\
\text { Öncesi }\end{array}$ & $\begin{array}{c}\text { Haddeleme } \\
\text { Sonrası }\end{array}$ & & & & \\
\hline$* \mathrm{E} / \mathbf{1}, \mathbf{8} / \mathbf{8 , 5} / \mathbf{1 0} / \mathbf{3 0}$ & 1840 & 1815 & 25 & 30 & 0,83 & 45 \\
\hline $\mathrm{E} / \mathbf{1}, \mathbf{8} / \mathbf{8 , 5} / \mathbf{1 0} / 60$ & 1840 & 1785 & 55 & 60 & 0,92 & 88 \\
\hline $\mathrm{E} / \mathbf{1}, \mathbf{8} / \mathbf{8}, \mathbf{5} / \mathbf{5 0} / \mathbf{3 0}$ & 1840 & 1815 & 25 & 30 & 0,83 & 55 \\
\hline $\mathrm{E} / \mathbf{1}, \mathbf{8} / \mathbf{8 , 5 / 5 0 / 6 0}$ & 1840 & 1785 & 55 & 60 & 0,92 & 83 \\
\hline $\mathrm{E} / \mathbf{1}, \mathbf{8} / \mathbf{3}, \mathbf{4} / \mathbf{1 0} / \mathbf{3 0}$ & 1840 & 1820 & 20 & 30 & 0,66 & 43 \\
\hline $\mathrm{E} / \mathbf{1}, \mathbf{8} / \mathbf{3 , 4} / \mathbf{1 0} / \mathbf{6 0}$ & 1840 & 1795 & 45 & 60 & 0,75 & 51 \\
\hline $\mathrm{E} / \mathbf{1}, \mathbf{8} / \mathbf{3}, \mathbf{4} / \mathbf{5 0} / \mathbf{3 0}$ & 1840 & 1820 & 20 & 30 & 0,66 & 42 \\
\hline$E / 1,8 / 3,4 / 50 / 60$ & 1840 & 1795 & 45 & 60 & 0,75 & 68 \\
\hline
\end{tabular}

*1,8 mm kalınlığında ERD6112 kalite malzemenin, 8,5 $\mu \mathrm{m}$ pürüzlülüğünde merdane ile $10 \mathrm{~d} / \mathrm{dk}$ hızda, $30 \mu \mathrm{m}$ ezme miktarı verilerek haddeleme yapıldığı anlamına gelmektedir.

\section{E. Malzeme ve Merdane Pürüzlük Ölçümü}

Şekil 5.a’ da görülen cihazda haddeleme öncesi ve haddeleme sonrasında pürüzlülük ölçümü yapılmış ve malzemelerin pürüzlülüğ̈̈n ne oranda değiştiği tespit edilmiştir. Bu ölçümler malzemenin her iki yüzeyinden olmak üzere baş, orta ve son kısımlarından haddeleme yapılan yöne paralel ve dik bir şekilde 3' er kez yapılmış ve bu değerlerin aritmetik ortalama değerleri hesaplanarak nihai pürüzlülüğü bulunmuştur..

Şekil 5.b’ de gösterilen merdane yüzey pürüzlülük ölçümünde de merdanelerin 90' ar derecede 4 eksen boyunca haddeleme yapılan yöne paralel ve dik bir şekilde 3'er ölçüm yapılmış ve aritmetik ortalama değerleri hesaplanarak yüzey pürüzlülük değerleri bulunmuştur.

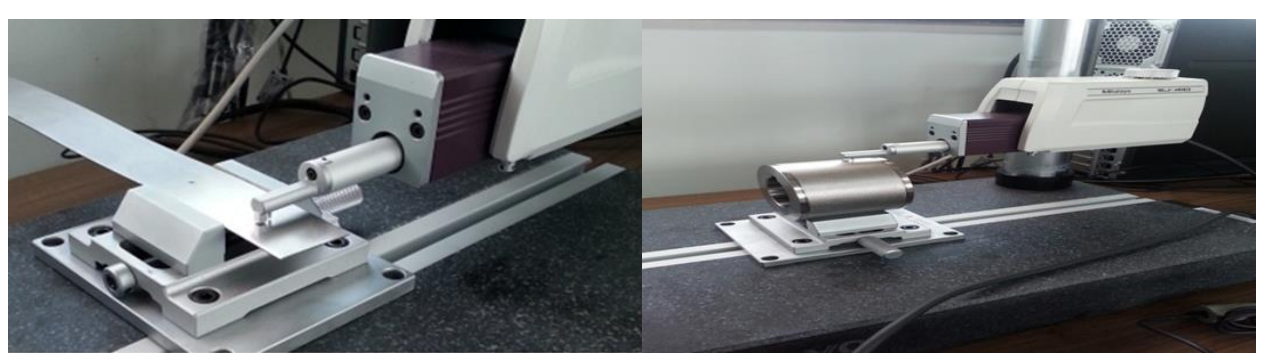

(a)

(b)

Şekil 5. Malzeme (a) ve merdane (b) yüzey pürüzlük ölçümü

\section{F. Pürüzlülük Transfer Oranı (PTO)}

Merdaneden malzemeye sirayet eden pürüzlülüğe ait transfer oranı (PTO) Eşitlik 1 deki denklem ile hesaplanmıştır [14].

$$
\text { PTO }[\%]=\left[\left(\mathrm{Ra}_{1}-\mathrm{Ra}_{0}\right) /\left(\mathrm{Ra}_{\mathrm{r}}-\mathrm{Ra}_{0}\right)\right] \times 100
$$

Eşitlikte belirtilen $\mathrm{Ra}_{1}$ ifadesi malzemenin hadde yapıldıktan sonraki yüzeyde oluşan pürüzlülüğü, $\mathrm{Ra}_{\mathrm{r}}$ indisi kullanılan merdanedenin yüzeyindeki pürüzlülük değerini ifade etmektedir. $\mathrm{Ra}_{\mathrm{o}}$ indisi ise yapılan deneysel testler öncesindeki yüzey pürüzlülük değerini ifade etmektedir. Bu formüle göre bütün malzemelerin pürüzlülük transfer oranı yüzde olarak excel de hesaplanmış ve grafiksel olarak bulgular ve tartışma bölümünde yorumlanmıştır. 


\section{BULGULAR VE TARTIŞMA}

ERD6112 kalite sac malzeme için test öncesi yapılan yüzey pürüzlülük ölçümünde pürüzlülük değeri 1,654 $\mu \mathrm{m}$ olarak tespit edilmiştir. Aynı şekilde bu malzemenin test sonrasında 8 adet numune üzerinde yapılan yüzey pürüzlülük ölçümünde Tablo 3 ' de verilen haddeleme parametreleri göz önüne alınarak haddelendikten sonra malzemenin her iki yüzeyi için baş, orta ve sonunda Şekil 6' da gösterilen haddeleme yönüne paralel ve haddeleme yönüne dik olmak üzere 3' er ölçüm yapılmış ve bulunan değerlerin aritmetik ortalaması alınarak test numunelerinin yüzey pürüzlülük değerleri elde edilmiştir.

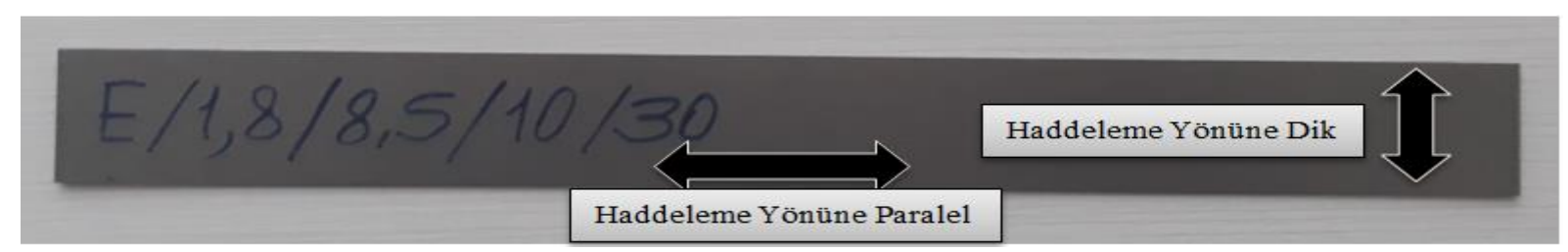

Şekil 6. Malzeme yüzey pürüzlülük ölçüm yönleri

Yapılan ölçümler sonucunda ERD6112 kalite sac malzemeye ait haddeleme öncesi tek bir yüzeye ait pürüzlülük değeri, haddeleme sonrası ise alt ve üst yüzeylerden boyuna ve enine yüzey pürüzlülük ölçümleri yapılmış, elde edilen sayısal verilerin genel ortalama değerleri ve standart sapma değerleri Tablo 5' de gösterilmiştir.

Tablo 5. ERD6112 Malzemeye ait yüzey pürüzlülük değerleri

\begin{tabular}{|c|c|c|c|c|c|c|}
\hline \multirow{3}{*}{$\begin{array}{c}\text { Haddeleme } \\
\text { Parametreleri }\end{array}$} & \multirow{3}{*}{$\begin{array}{l}\text { Haddeleme } \\
\text { Öncesi }\end{array}$} & \multicolumn{4}{|c|}{ Malzeme Yüzey Pürüzlülüğü $(\mu \mathrm{m})$} & \multirow{3}{*}{$\begin{array}{c}\text { Standart } \\
\text { Sapma }\end{array}$} \\
\hline & & & Haddele & Sonrası & & \\
\hline & & & & Ort. & Genel Ort. & \\
\hline \multirow{2}{*}{$* \mathrm{E} / \mathbf{1}, \mathbf{8} / \mathbf{8}, \mathbf{5} / \mathbf{1 0} / \mathbf{3 0}$} & \multirow{2}{*}{1,654} & Üst Yüzey & $\begin{array}{c}\text { Boyuna } \\
\text { Enine }\end{array}$ & $\begin{array}{l}3,533 \\
3,005\end{array}$ & \multirow[b]{2}{*}{3,029} & $\pm 0,994$ \\
\hline & & Alt Yüzey & $\begin{array}{l}\text { Boyuna } \\
\text { Enine }\end{array}$ & $\begin{array}{l}2,692 \\
2,884\end{array}$ & & $\pm 0,17$ \\
\hline \multirow{2}{*}{$\mathrm{E} / \mathbf{1}, \mathbf{8} / \mathbf{8}, \mathbf{5} / \mathbf{1 0} / \mathbf{6 0}$} & \multirow{2}{*}{1,654} & Üst Yüzey & $\begin{array}{c}\text { Boyuna } \\
\text { Enine }\end{array}$ & $\begin{array}{l}6,156 \\
5,378 \\
\end{array}$ & \multirow[b]{2}{*}{5,293} & $\pm 1,345$ \\
\hline & & Alt Yüzey & $\begin{array}{c}\text { Boyuna } \\
\text { Enine }\end{array}$ & $\begin{array}{l}5,702 \\
3,937\end{array}$ & & $\pm 1,157$ \\
\hline \multirow{2}{*}{$\mathrm{E} / \mathbf{1}, \mathbf{8} / \mathbf{8 , 5 / 5 0 / 3 0}$} & \multirow{2}{*}{1,654} & Üst Yüzey & $\begin{array}{c}\text { Boyuna } \\
\text { Enine }\end{array}$ & $\begin{array}{l}4,212 \\
3,791 \\
\end{array}$ & \multirow{2}{*}{3,904} & $\pm 0,793$ \\
\hline & & Alt Yüzey & $\begin{array}{c}\text { Boyuna } \\
\text { Enine }\end{array}$ & $\begin{array}{l}4,365 \\
3,248 \\
\end{array}$ & & $\pm 0,827$ \\
\hline \multirow{2}{*}{$\mathrm{E} / \mathbf{1}, \mathbf{8} / \mathbf{8 , 5 / 5 0 / 6 0}$} & \multirow{2}{*}{1,654} & Üst Yüzey & $\begin{array}{c}\text { Boyuna } \\
\text { Enine }\end{array}$ & $\begin{array}{l}6,040 \\
4,853 \\
\end{array}$ & \multirow{2}{*}{5,468} & $\pm 0,858$ \\
\hline & & Alt Yüzey & $\begin{array}{c}\text { Boyuna } \\
\text { Enine }\end{array}$ & $\begin{array}{l}4,582 \\
6,395 \\
\end{array}$ & & $\pm 1,909$ \\
\hline \multirow{2}{*}{$\mathrm{E} / \mathbf{1}, \mathbf{8} / \mathbf{3}, \mathbf{4} / \mathbf{1 0} / \mathbf{3 0}$} & \multirow{2}{*}{1,654} & Üst Yüzey & $\begin{array}{c}\text { Boyuna } \\
\text { Enine }\end{array}$ & $\begin{array}{l}2,411 \\
1,917\end{array}$ & \multirow{2}{*}{2,001} & $\pm 0,419$ \\
\hline & & Alt Yüzey & $\begin{array}{c}\text { Boyuna } \\
\text { Enine }\end{array}$ & $\begin{array}{l}1,849 \\
1,866\end{array}$ & & $\pm 0,142$ \\
\hline \multirow{2}{*}{$\mathrm{E} / \mathbf{1}, \mathbf{8 / 3}, \mathbf{4} / \mathbf{1 0} / \mathbf{6 0}$} & \multirow{2}{*}{1,654} & Üst Yüzey & $\begin{array}{c}\text { Boyuna } \\
\text { Enine }\end{array}$ & $\begin{array}{l}2,382 \\
1,876 \\
\end{array}$ & \multirow{2}{*}{2,234} & $\pm 0,408$ \\
\hline & & Alt Yüzey & $\begin{array}{l}\text { Boyuna } \\
\text { Enine }\end{array}$ & $\begin{array}{l}2,215 \\
2,461\end{array}$ & & $\pm 0,209$ \\
\hline \multirow{2}{*}{$\mathrm{E} / \mathbf{1}, \mathbf{8} / \mathbf{3}, \mathbf{4 / 5 0 / 3 0}$} & \multirow{2}{*}{1,654} & Üst Yüzey & $\begin{array}{l}\text { Boyuna } \\
\text { Enine }\end{array}$ & $\begin{array}{l}2,082 \\
1,796\end{array}$ & \multirow{2}{*}{2,055} & $\pm 0,249$ \\
\hline & & Alt Yüzey & $\begin{array}{l}\text { Boyuna } \\
\text { Enine }\end{array}$ & $\begin{array}{l}2,380 \\
1,963\end{array}$ & & $\pm 0,421$ \\
\hline \multirow{2}{*}{$\mathrm{E} / \mathbf{1}, \mathbf{8} / \mathbf{3}, \mathbf{4 / 5 0 / 6 0}$} & \multirow{2}{*}{1,654} & Üst Yüzey & $\begin{array}{c}\text { Boyuna } \\
\text { Enine }\end{array}$ & $\begin{array}{l}2,723 \\
2,490 \\
\end{array}$ & \multirow{2}{*}{2,614} & $\pm 0,285$ \\
\hline & & Alt Yüzey & $\begin{array}{l}\text { Boyuna } \\
\text { Enine }\end{array}$ & $\begin{array}{l}2,696 \\
2,548\end{array}$ & & $\pm 0,354$ \\
\hline
\end{tabular}

*1,8 mm kalınlığında ERD6112 kalite malzemenin, 8,5 $\mu \mathrm{m}$ pürüzlülüğünde merdane ile $10 \mathrm{~d} / \mathrm{dk}$ hızda, $30 \mu \mathrm{m}$ ezme miktarı verilerek haddeleme yapıldığı anlamına gelmektedir. 


\section{A. Hız İlişkisi}

Yapılan testler neticesinde ERD6112 kalite malzeme için Şekil 7' de gösterilen grafiğe göre 3,4 $\mu \mathrm{m}$ ve $8,5 \mu \mathrm{m}$ pürüzlülük değerindeki merdaneler ile yapılan haddeleme işleminde $30 \mu \mathrm{m}$ ve $60 \mu \mathrm{m}$ ezme oranı verildiğinde aynı ezme oranında yüksek devirlerde $(50 \mathrm{~d} / \mathrm{dk})$ pürüzlülük transferinin fazla olduğu tespit edilmiştir. $10 \mathrm{~d} / \mathrm{dk}$ veya $50 \mathrm{~d} / \mathrm{dk}^{\prime}$ lık hızlarda ezme oranının artması pürüzlülük transferini artırmıştır.

Bulunan bu sonuçlar Ma ve arkadaşlarının bulmuş oldukları sonuçlarla paralellik arz etmektedir. Ma ve arkadaşları da aynı ezme oranlarında fakat farklı hızlarda $(5 \mathrm{~d} / \mathrm{dk}, 30 \mathrm{~d} / \mathrm{dk}$ ve $60 \mathrm{~d} / \mathrm{dk})$ yapmış oldukları çalışmada haddeleme hızının artmasıyla yüzey pürüzlülüğünün arttığını gözlemlemişlerdir [15].
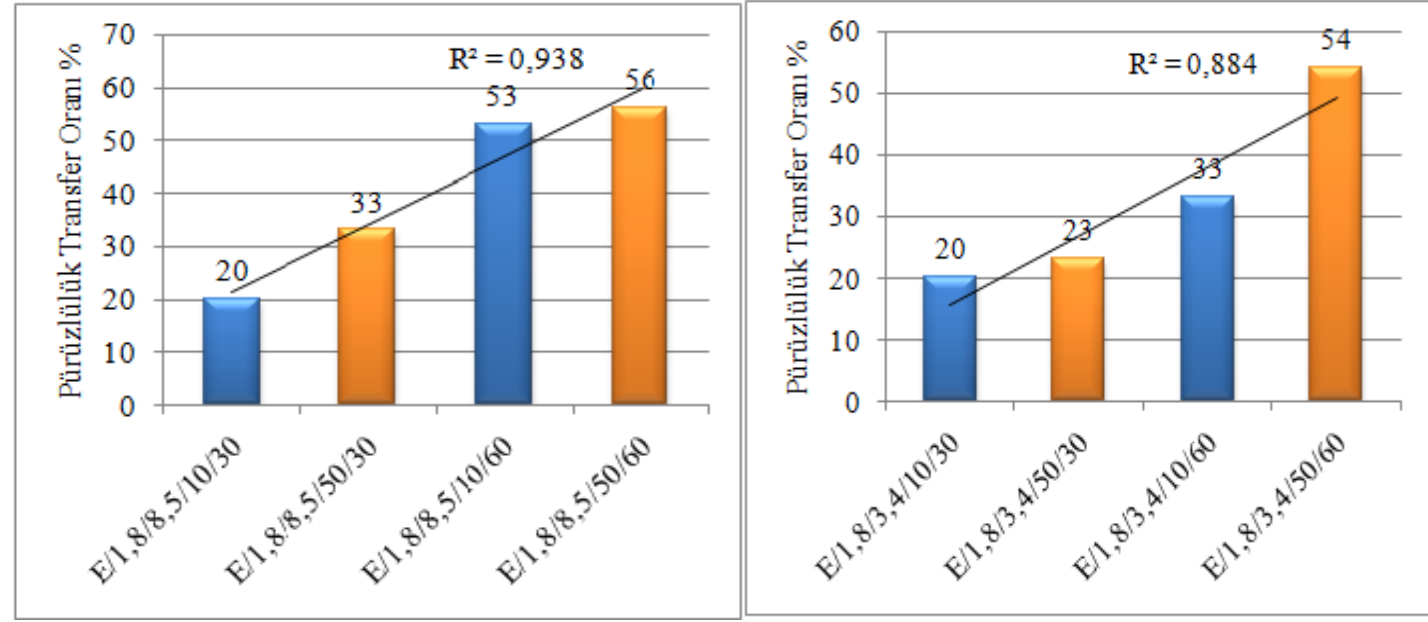

Şekil 7. ERD6112 kalite malzemeye ait pürüzlülük transfer oranı - hız ilişkisi

\section{B. Ezme Oranı İlişkisi}

Yapılan testler sonucunda Şekil 8' deki grafikte görüldüğü üzere hızın aynı ezme miktarının farklı olduğu durumda gerçekleştirilen haddeleme işlemlerinde ezme miktarının fazla olması $(60 \mu \mathrm{m})$ durumunda pürüzlülük transfer oranının ve haddeleme kuvvetinin yüksek olduğu görülmüştür.

Bu sonuç ile Kijima' nın bulmuş olduğu sonuçlar arasında paralellik olduğu söylenebilir. Kijima da 50 mm ve $250 \mathrm{~mm}$ yarıçaplarında ki merdaneler ile yapmış olduğu deneysel çalışmada ezme miktarının yüksek olması durumunda pürüzlülük transfer oranında ve haddeleme kuvvetinde artış olduğunu gözlemlemiştir [14].

Wu ve arkadaşları da ezme miktarının artmasıyla birlikte haddeleme kuvvetinin ve pürüzlülük transferinin arttığı sonucuna ulaşmışlardır. Pürüzlülük transferinin yüzde yüz gerçekleşmesinin mümkün olmadığını, çok küçük ezme oranlarında sadece elastik şekil değişimi olduğundan hemen hemen hiç pürüzlülük transferi gerçekleşmediğini belirtmişlerdir [16]. Genel olarak söylenebilir ki: pürüzlülük transferi küçük ezme oranlarında azalmaktadır. Bu durum bir ütüleme haddesi olan temper haddelemede göz önünde bulundurulması gereken hususlardandır. Haddeleme hızının artırılması ile bu durum telafi edilebilir. Böylece hızın artması ile üretim miktarının da artması sağlanmış olur [6]. 


\begin{tabular}{|c|c|c|}
\hline & $\begin{array}{l}\text { BŞEÜ Fen Bilimleri Dergisi } \\
6(2), 344-356,2019\end{array}$ & $\begin{array}{r}\text { BSEU Journal of Science } \\
\text { DOI: } 10.35193 / \text { bseufbd.599469 }\end{array}$ \\
\hline $\begin{array}{l}\text { BiLECIK ȘEYH EDEBALI } \\
\text { UN IVER I I TES S }\end{array}$ & & e-ISSN: $2458-7575$ (http://dergipark.gov.tr/bseufbd) \\
\hline
\end{tabular}
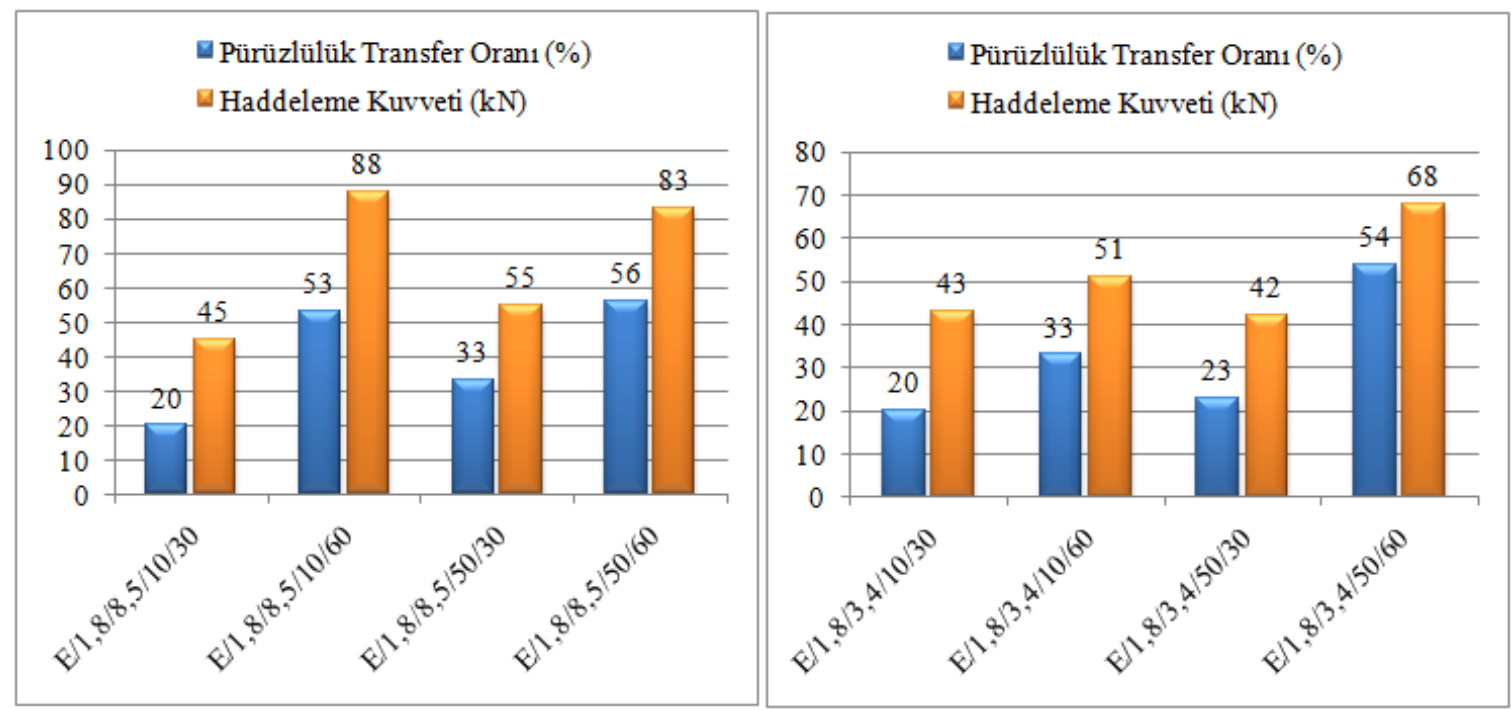

Şekil 8. ERD6112 kalite malzemeye ait ezme oranı-pürüzlülük transferi-haddeleme kuvveti ilişkisi

\section{Hadde Kuvveti İlișkisi}

Elde edilen deney sonuçlarına göre Şekil 9' daki grafikte her iki merdanede de birim hadde kuvvetindeki artış ile beraber pürüzlülük transferide artmıştır.

Kijima $50 \mathrm{~mm}$ ve $250 \mathrm{~mm}$ yarıçaplarında, $3,1 \mu \mathrm{m}$ ve $8 \mu \mathrm{m}$ pürüzlük değerindeki merdaneler ile yapmış olduğu deneylerde hadde kuvvetinin artması ile pürüzlük transfer oranının arttığını tespit etmiştir. Wentink ve arkadaşları da hadde kuvvetindeki artışla beraber pürüzlük transferinin arttığı sonucunu gözlemlemişlerdir [17].

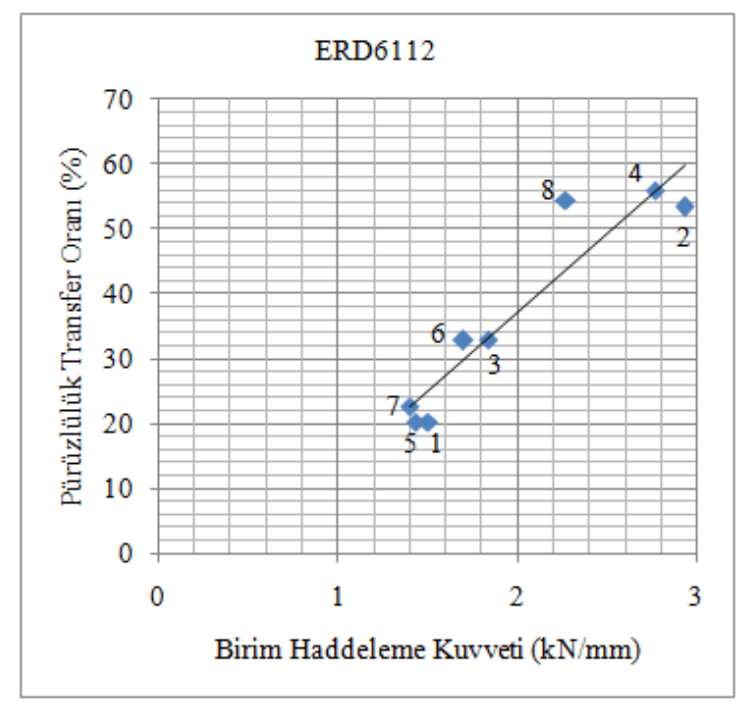

Şekil 9. ERD6112 kalite malzemeye ait hadde kuvveti-pürüzlülük transferi grafiğgi

\begin{tabular}{|c|c|c|c|}
\hline \multirow{2}{*}{$\begin{array}{l}\text { 1:*E/1,8/8,5/10/30 } \\
\text { 5: E/1,8/3,4/10/30 }\end{array}$} & 2:E/1,8/8,5/10/60 & 3:E/1,8/8,5/50/30 & 4:E/1,8/8,5/50/60 \\
\hline & 6: $E / 1,8 / 3,4 / 10 / 60$ & $7: E / 1,8 / 3,4 / 50 / 30$ & 8:E/1,8/3,4/50/60 \\
\hline
\end{tabular}




\section{Standart Sapma-Ezme Miktarı İlişkisi}

Sac malzemelerin özellikle otomobil ve beyaz eşya üretimi gibi yüzey görünümünün önemli olduğu kullanım alanlarında, malzemenin yüzey pürüzlülük değerinin belli bir seviyede olması istenmesinin yanı sıra, pürüzlülük dağılımının dar bir aralıkta olması da gerekmektedir. Malzeme yüzeyinde yapılan çok sayıda pürüzlülük ölçümü sayesinde, pürüzlülük transfer oranına ilaveten, pürüzlülük dağılımındaki homojenliğin bir göstergesi olan standart sapma da hesaplanmıştır.

ERD6112 kalite malzemede her iki pürüzlülük değerindeki merdaneler ile yapılan haddeleme işlemindehız sabit iken ezme miktarının artması ile birlikte standart sapma değerinin arttığı gözlenmiştir. Ezme oranının sabit tutulup hızın arttığı durumda da standart sapma değerinin arttığı gözlenmiştir. Ayrıca 8,5 $\mu \mathrm{m}$ pürüzlülük değerindeki merdane ile yapılan haddeleme işleminde standart sapmanın daha yüksek değerde olduğu görülmektedir. Tablo 6' da ERD6112 kalite malzemeye ait deneysel standart sapma sonuçları verilmiştir.

Tablo 6. ERD6112 kalite malzemeye ait deneysel standart sapma sonuçları

\begin{tabular}{cc}
\hline Haddeleme Parametreleri & Deneysel Standart Sapma \\
\hline$* \mathbf{E} / \mathbf{1 , 8 / 8 , 5 / 1 0 / 3 0}$ & 0,582 \\
$\mathbf{E} / \mathbf{1}, \mathbf{8} / \mathbf{8 , 5 / 1 0 / 6 0}$ & 1,251 \\
$\mathbf{E} / \mathbf{1}, \mathbf{8} / \mathbf{8 , 5 / 5 0 / 3 0}$ & 0,810 \\
$\mathbf{E} / \mathbf{1}, \mathbf{8} / \mathbf{8 , 5 / 5 0 / 6 0}$ & 1,354 \\
$\mathbf{E} / \mathbf{1 , 8 / 3 , 4 / 1 0 / 3 0}$ & 0,281 \\
$\mathbf{E} / \mathbf{1 , 8 / 3 , 4 / 1 0 / 6 0}$ & 0,309 \\
$\mathbf{E} / \mathbf{1 , 8 / 3 , 4 / 5 0 / 3 0}$ & 0,315 \\
$\mathbf{E} / \mathbf{1 , 8 / 3 , 4 / 5 0 / 6 0}$ & 0,320 \\
\hline
\end{tabular}

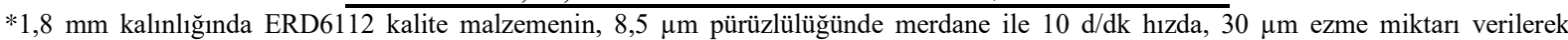
haddeleme yapıldığı anlamına gelmektedir.

\section{SONUÇ}

Yapılan bu deneysel çalışma ile istenilen yüzey şartlarında malzeme için yalnızca yüzeyi pürüzlendirilmiş merdane kullanımının yeterli olmadığı tespit edilmiştir. Çünkü ERD6112 kalite sac malzemede aynı merdane ile farklı haddeleme koşullarında birbirinden farklı değerde yüzey pürüzlülüğüne sahip sonuçlar tespit edilmiştir. Literatür çalışmaları incelendiği takdirde haddeleme işleminin farklı malzemelerde uygulandığ 1 görülmektedir. Alüminyum ve alaşımları (Döküm AlCu alaşım, 7075 T6, AA2014, AA 7178, AA 7075, 6061T6, Al 6061) ile çelik (plastik kalıp çelikleri, çelik, 1sıl işlem görmüş ve temperlenmiş çelik, sertleştirilmiş çelik, AISI 5140, St37, X5CrNiMo17-12-2) en çok kullanılan uygulama malzemesi olarak karşımıza çıkmaktadır. Bunun sebebinin alüminyum alaşımlarının ve çeliklerin endüstrideki kullanım alanının çok geniş olması olarak söylenebilir. Ayrıca literatürde polimerler, pirinç, titanyum ve bakır gibi bazı malzemelerin de haddeleme işlemine tabi tutuldukları ve deneysel bazı çalışmaların yapıldığı görülmektedir.

Yapılan bu deneysel çalışma ile istenilen yüzey şartlarında malzeme için yalnızca yüzeyi pürüzlendirilmiş merdane kullanımının yeterli olmadığı tespit edilmiştir. Çünkü malzemede aynı merdane ile farklı haddeleme koşullarında birbirinden farklı değerde yüzey pürüzlülüğü sonucu elde edilmiştir.

ERD6112 kalite malzeme için haddeleme kuvvetini artıran her parametre ile birlikte pürüzlük transferinin arttığı görülmüştür. ERD6112 kalite malzemede her iki pürüzlükte de aynı ezme oranlarında hızın 10 d/dk' dan 50 d/dk' ya çıkarılmasıyla pürüzlülük transferinin \%63' lere kadar arttığı gözlenmiştir. Aynı hız farklı ezme oranları verilerek gerçekleştirilen haddelemede ezme oranının $30 \mu \mathrm{m}$ ' den $60 \mu \mathrm{m}$ ' ye çıkarılması ile haddeleme kuvvetinin \%96' lara, pürüzlülük transferinin ise \%163' lere kadar arttığ1 gözlenmiştir. Ezme miktarı arttırıldığında malzeme yüzey pürüzlülüğündeki artışın yanı sıra pürüzlülük dağılım aralığının genişlediği farkedilmiştir. Bu genişleme çok pürüzlü merdanelerle yapılan testlerde daha belirgindir. Ezme oranı $30 \mu \mathrm{m}$ ' den $60 \mu$ m'ye çıkarıldığında az pürüzlü merdanelerle yapılan testlerde standart sapma 0,281 ' den 0,320 ' ye yükselerek en fazla \%14 artış gösterirken; çok pürüzlü merdanelerle yapılan testlerde 0,582' den 1,354' e yükselerek en fazla \%133 artış göstermiştir. Yapılan deneysel çalışmadan elde edilen sonuçlar neticesinde ERD6112 kalitedeki malzeme yüzeyinde daha yüksek derecede pürüzlülük olması istendiğinde haddeleme 
hızının artırılması tercih edilmelidir. Bu neticede üretim de de artış olacaktır. Ancak haddeleme hızı artırıldığ zaman haddeleme kuvvetinin de artacağı ve bu durumun hem merdane giderlerinde bir artışa hem de hadde düzeneğinde hasarlanmalardan dolayı üretimde aksaklıklara sebebiyet vereceğini unutmamak gerekir.

Yapılan bu çalışma ile şu sonuçlarda elde edilmiştir.

$\checkmark$ Deney sonuçlarına göre hadde hızının artmasıyla birlikte haddeleme kuvveti her zaman artmamış azalma eğilimi göstermesinin yanı sıra bazen de sabit kalmıştır.

$\checkmark$ Pürüzlülük değeri için net bir bilgi elde edilememiş ve bazı deneylerde üst yüzeyde, bazı deney sonuçlarına göre de alt yüzeyde fazla olduğu gözlenmiştir. gözlenmiştir.

$\checkmark$ 8,5 $\mu \mathrm{m}$ pürüzlülük değerinde ki merdanede standart sapma değerinin daha fazla olduğu

$\checkmark$ Bu çalışma neticesinde ERD6112 kalite sac malzemelede temper haddeleme ile malzeme yüzeyinde homojen bir yüzey pürüzlülüğü elde edilmiştir.

\section{KAYNAKLAR}

[1] Sönmez, F. (2009). Haddeleme işleminin yüzey pürüzlülüğ̈̈ ve yüzeysertliğine etkilerinin incelenmesi. Yüksek Lisans Tezi, Gazi Üniversitesi Fen Bilimleri Enstitüsü Makine Eğitimi, 123, Ankara.

[2] Davies, D. J., \& Oelmann, L. A. (1985). "Metallurgical Processes and Production Technology", 2nd. Ed., PITMAN Publishing Limited, London, 230.

[3] Aran, A. \& Demirkol, M. (1995). Plastik Şekil Verme Teknolojisi, İTÜ, İstanbul, 102-104.

[4] Langlands T.A.M., \& McElwain D.L.S. (2002). A modifed Hertzian foil rolling model: approxi mations based on perturbation methods, Int. J. Mech., 44, 1715-1730

[5] Die Bibliothek Der Technik; Achenbach Buschütten. (1999). Aluminium rolling mill technology.

[6] Çolak, B. (2018). Soğuk haddelemede pürüzlülük transferini etkileyen haddeleme parametrelerinin ve malzeme özelliklerinin deneysel olarak incelenmesi. Doktora Tezi, Karabük Üniversitesi Fen Bilimleri Enstitüsü Makine Mühendisliği Anabilim Dalı, 111, Karabük.

[7] El-Axir. (2000). An investigation into roller burnishing. International Journal of Machine Tools \& Manufacture, 40, 1603-1617.

[8] Hassan, A. D., \& Maqableh, A. M. (2000). The effects of initial burnishing parameters on non-ferrous components. Journal of Materials Processing Technology, 102, 115-121.

[9] Hassan, A.M. (1997). An Investigation into the surface characteristics of burnished cast Al-Cu Alloys. Int. J. Mach. Tools Manufact. 37, 813-821.

[10] Hassan, A. M., \& Momani, A. M. S. (2000). Further improvements in some properties of shot peened components using the burnishing process. International Journal of Machine Tools \& Manufacture, 40, $1775-1786$.

[11] Ginzburg, V. B. \& Ballas, R. (2000). Classification of Steel. Flat Rolling Fundamentals, Marcel Dekker, Inc., New York, 81-85.

[12] Erdemir, 2018.

https://www.erdemir.com.tr/Sites/1/upload/files/Urun_Katalogu-2017-1269.pdf. 
[13] Karaağaç, İ., \& Özdemir, A. (2011). Erdemir 6112 sac malzemenin hidromekanik derin çekme yöntemiyle şekillendirilebilirliği, Gazi Üniversitesi.

[14] Kijima, H. (2013). Influence of rollradius on roughness transfer in skin-passrolling of steelstrip. J. Mat. Proc. Technol, 214, 1111-1119.

[15] Ma, B., Tieu, A. K., Lu, C., \& Jiang, Z. (2002). An experimental investigation of steel surface characteristic transfer by cold Rolling. Journal Of Materials Processing Technology, 125-126: 657-663.

[16] Wu, C., Zhang, L., Qu, P., Li, S., \& Jiang, Z. (2018). A simple approach for analysing the surface texture transfer in cold rolling of metal strips. International Journal Of Advanced Manufacturing Technology, 95 (1-4): 597-608.

[17] Wentink, D. J., Matthews, D., Appelman, N. M., \& Toose, E. M. (2015). A generic model for surface texture development, wear and roughness transfer in skin pass Rolling. Wear, 328-329, 167-176. 